International Journal on Integrating Technology in Education (IJITE) Vol.7, No.2, June 2018

\title{
ENHANCING STUDENTS' LEARNING AND SATISFACTION THROUgh THE USE OF Social MEDIA
}

\author{
Mohammad Alshayeb \\ Information and Computer Science Department, King Fahd University of Petroleum \& \\ Minerals, Dhahran 31261, Saudi Arabia
}

\begin{abstract}
Communication in and out the classroom is an essential component for education. As the technology emerges, there is a need to adopt to the new technologies to enhance students' learning experience. Social media technologies provide informal communication methods that promote student engagement and satisfaction by removing communication barriers. In this paper, we report our experience in using different social media technologies to enhance students' learning experience and satisfaction with the course. We perform our experiment in software project management course and conduct a survey to assess the students' perspective towards using these different social media technologies in enhancing their learning and satisfaction. Results show that students are satisfied and feel that their learning experience has improved when using social media for class communication.
\end{abstract}

\section{KEYWORDS}

Student learning experience., student satisfaction, social media

\section{INTRODUCTION}

Research show that the use of instructional technology has improved students' learning [1-4]. Different computer technologies have been utilized in the higher education for different purposes. Instructors used communication [5] and mobile [6] tools to enhance students' learning. Multimedia was also utilized [7, 8]. Wikis, portals, blogs and instant messaging [9-11] were also used.

Student engagement has positive impact on students' achievement [12]. Using technology in teaching can help students increase their capability for understanding [13]. students taught with a technology-based approach outperformed and were more satisfied than students taught with the traditional teaching methods [14]. Gunuc and Kuzu [12] evaluated the impact of technology on student engagement and found that the use of technology in and out the class increased student engagement.

Mobile technologies were also found to be effective in teaching and learning [15-18]. Barbosa et al. reported that the use of mobile in teaching improved the learning and the interaction between students[19]. Game-based learning [20] was also found to be effective in enhancing students' learning process. Watson et al. presented a case study of the in-class use of a video game for teaching high school history [21]. However, the use of technology may have negative impact[2225]. Bray and Tangney [6] conducted a study to evaluate the impact of using mobile technologies in students' engagement; they found that the use of mobile technologies increases student engagement.

Communication tools not only should be usable, but they should also be engaging [26].Social media technologies provide interactive environment for communication and thus can engage students. Dyson et al. [27] evaluate the impact of using Facebook on student engagement. They 
International Journal on Integrating Technology in Education (IJITE) Vol.7, No.2, June 2018

divided a large class into two groups: two third of the class to use Facebook and one third not to use Facebook. They found that students who did not view Facebook reported lower engagement and understanding of the in-class discussion. In another study, Rashid and Asghar [28] evaluated the impact of using technology student engagement and found that the use of technology has a direct positive relationship with students' engagement. Imlawi et al. [29] reported that when the instructor uses course-based online social networks to communicate with them,students are more engaged, motivated and satisfied.

This paper is an extended version of the our previous work [30] and provides more details on our experience in using three different social media technologies in a software project management course. The use of technology in this course was started in 2011 by using Facebook. During those years, students have shown great interest in using Facebook for class communication. However, after four years of using Facebook, the students reported that they are less motivated to use Facebook for class communication. They were dissatisfied and requested to use another technology. The instructor evaluated available technologies and based on the student feedback, the instructor started to use WhatsApp for one year. The use of WhatsApp was a successful, however, due to the need for personalized communication, there was a need to search for another tool. After evaluating the available technologies, Slack [31] was selected to be used.

The reminder of this paper is organized as follows:Section 2 describes the course details. Section 3 presents discussion about the used tools. In Section 4, we present the evaluation and the discussion. Finally, section 5 presents the conclusion and the future work.

\section{Course Details}

We used the social media technologies in software project management course. The course is a 300-level course that is given as a core course to software engineering students at King Fahd University of Petroleum and Minerals (KFUPM). Students in other disciplines such as computer science, computer engineering and systems engineering can take the course as an elective. The course covers the ten-project management knowledge area as specified by PMBOK [32].

The course has four objectives, one of which is to enhance communication skills. Students have to work in teams to complete a project about writing a complete project plan which. In addition, they have to work in teams for three other assignments. Therefore, this requires lots of interaction between students themselves which tends to contribution in improving their oral and writing communication skills are required. Furthermore, the course requires lots of interaction with the course instructor for feedback and class discussion

Due to the high need for communication, the instructor decided to utilize software tools to facilitate the communication. Even through the university provides Blackboard [33] as a main tool, the instructor decided to use social media technologies. The use of the social media tools was triggered mainly by the students requests in addition the instructor decided to use them as they are more accessible to the students and students will be more interested in using them. The social media was mainly sin the course for:

- Announcements: Students are almost always online on the social media and hence, any announcement posted will be viewed immediately to the students. All announcements related to the course we posted using the selected social media.

- Response to urgent questions: Before submission deadlines, students used to ask many questions, with the availability of the social media any time everywhere, the instructor was able to respond to all students' question in timely manner.

- Discussion Questions by the Instructor: The instructor utilized the availability of the students online most of the time to post discussion questions. These questions attracted 
International Journal on Integrating Technology in Education (IJITE) Vol.7, No.2, June 2018

many students to participate especially when the answer is not obvious, this generated lost of discussion which in terns tend to enhance students' communication skills.

- Discussion Questions by the Students: A student group was assigned every week to answer all questions posted by other students. This was done mainly to enhance the students' skills in problem solving. The instructor used to monitor the discussion and will interfere when needed.

- Online Office Hours: A few online office hours sessions we scheduled before the exams. This made it easier for students to get answers for their questions

\section{Social Media ToOLS}

Students in 2011 requested to use Facebook for class communication. At that time, the use of Facebook was popular. The instructor evaluated all available social media tools and based on the student's request, the instructor decided to use Facebook. To evaluate the effectiveness of all technologies used in the course, the instructor conducts a survey at the end of every semester.

At the end of 2012, in response to the question "What technologies, used in the course, improved your learning the most?" fifteen students out of the 22 students reported Facebook. This was a good indicator that the use of Facebook was a success.

In 2014 survey, the results were different. Most students reported that Facebook is not appropriate to be used, students' specific comments are shown below:

- "Unfortunately, Facebook is dying in our region and I only open it for this group"

- "I do not recommend Facebook in the next offering"

- "To me, the use of Facebook was really a bad experience"

- "It is better to use technology other than Facebook"

- "NOT using Facebook"

- "It was hard for me to check on Facebook, also using WhatsApp group could be a good and faster way"

Based on this response, the instructor started to look for more appropriate tools to be used. The decision was to use WhatsApp as it is a very popular tool in addition to the requests by the students. The use of WhatsApp was also a success, however, since there is a need for personalized communication, the instructor decided to search for more appropriate tool. Slack [31]was selected to be used as a new method for communication as it includes all features of WhatsApp and more in addition, it is widely used in software projects.

\section{Evaluation}

As indicated in section 0 , at the end of each semester, the course instructorconducts a survey to evaluate student's engagement and satisfaction. The details of surveys to evaluate these social media technologies are discussed in the following subsections.

\subsection{FАСЕВОOK}

In this section, a discussion of the survey result is presented. Facebook was first used in 2011. In response to question "The use of Facebook for class communication was effective and useful and enhanced my learning experience", it can be seen that $95 \%$ of the students either strongly agree or agree that using Facebook for class communication was effective and useful and enhanced their learning experience as shown in Figure 1. 


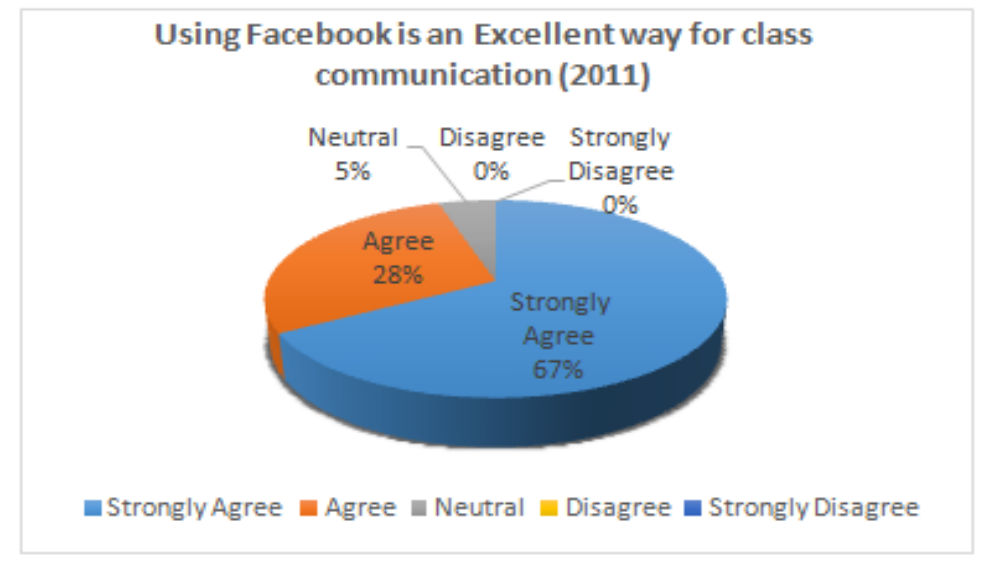

Figure 1: Using Facebook for communication (2011)

In response to a question "Which technologies, used in the course, improved your learning the most?", 15 students out of 22 selected Facebook. The survey clearly shows that students feel that Facebook was effective for class communication and they were also satisfied by using it.

The results of 2014 survey showed that students are not supporting to use Facebook. As shown in Figure 2, there are $25 \%$ of the students were dissatisfied or feel that using Facebook for class communication was not effective nor useful to enhance their learning experience. This feedback motivated the instructor to search for an alternative tool for class communication. After evaluating the available technologies, WhatsApp was selected as the new tool for the class.

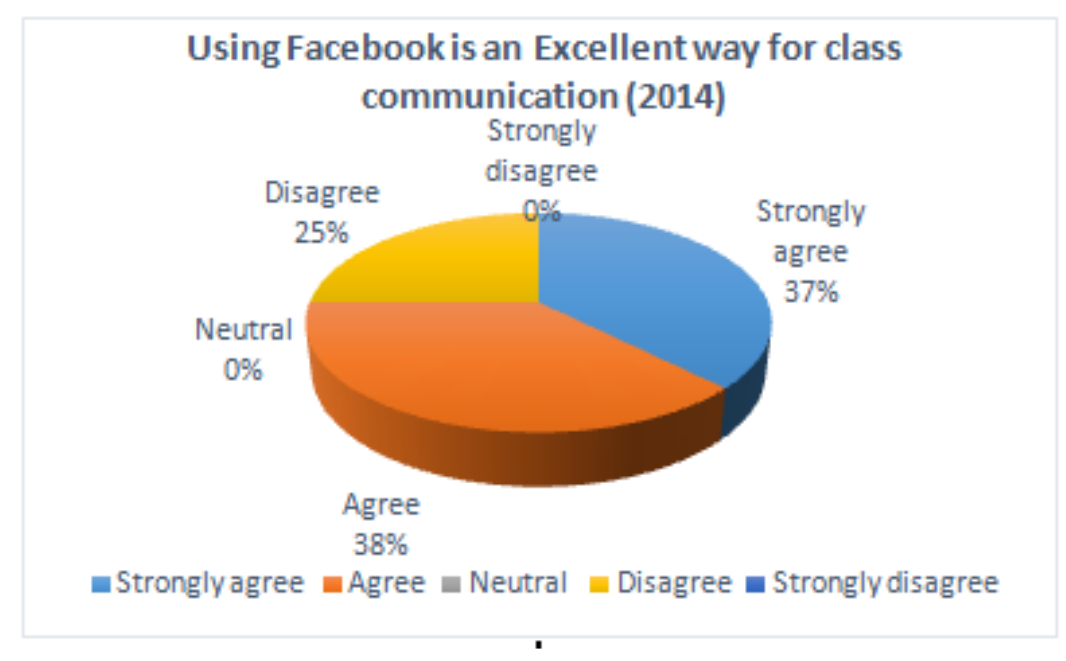

Figure 2. Using Facebook for communication (2014)

\subsection{WHATSAPP}

WhatsApp was used for two semesters, the feedback for the two times was positive. The last survey conducted of using WhatsApp was done in 2016. As shown in Figure 3 to Figure 5, students' feedback is positive and show high satisfaction with using WhatsApp. Figure 3 shows that $86 \%$ of the students either strongly agree or agree that using WhatsApp is an excellent way for class communication. 
International Journal on Integrating Technology in Education (IJITE) Vol.7, No.2, June 2018

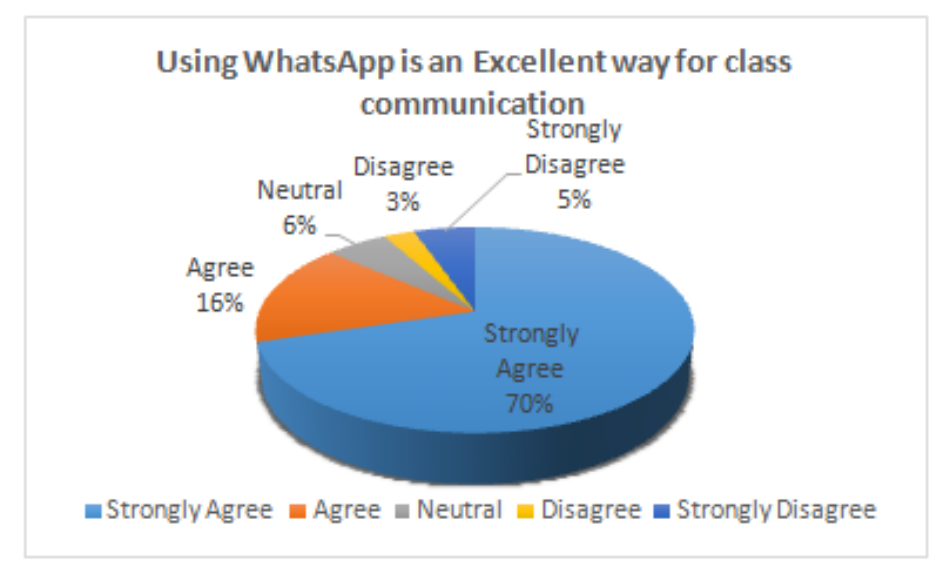

Figure 3. Using WhatsApp for communication

Figure 4 shows that $83 \%$ of the students either strongly agree or agree that discussion questions posted on that WhatsApp group were useful.

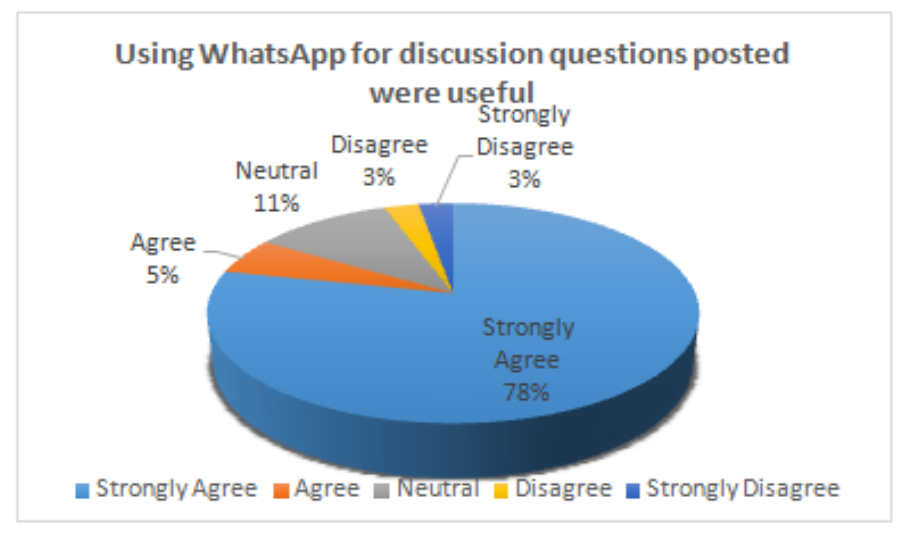

Figure 4. Using WhatsApp for discussion questions

Figure 5 shows that $87 \%$ of the students recommend using WhatsApp in the future offering of the course.

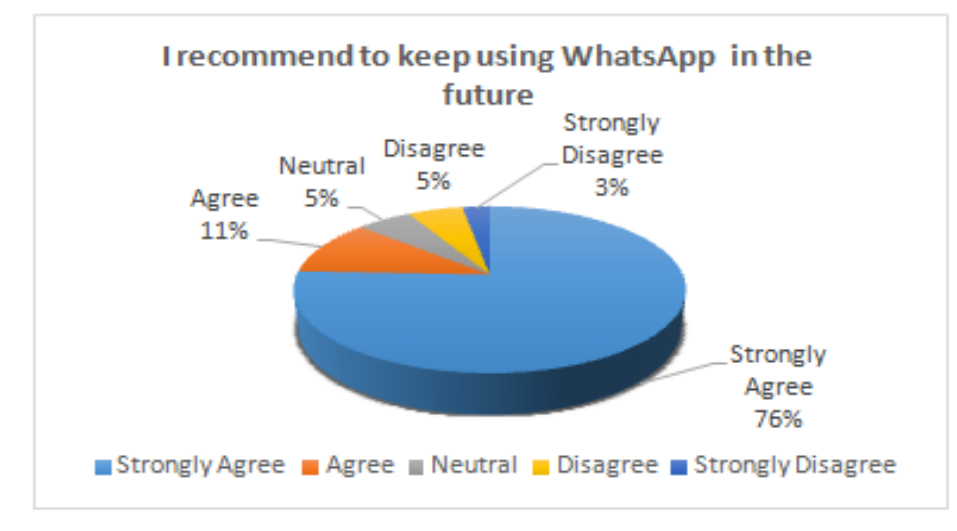

Figure 5. Recommending using WhatsApp in the Future 
Results of using WhatsApp are positive and show that students were satisfied, however, the course requires personalized communication. To do that in WhatsApp, a group should be created for each team. This is not convenient, hence, there is a need to search for an alternative tool. After evaluating the alternative options that satisfy the needs, Slack was selected.

\subsection{SLACK}

Many software project teams use Slack for project communication. We found it effective for the course as it has all features of WhatsApp has in addition to being able to have personalized communication. The instructor needs to communicate with each team individually to provide feedback and discuss the project submission. Slack provides a feature of different channels with different privileges. In addition, many other tools can be integrated with Slack.

Slack was used so far for two semesters ; a survey was conducted in 2017 and in 2018. Figure 6 shows the student response for using slack as a communication method in 2017. As can be seen, $65 \%$ of the students agree or strongly agree that using slack is an excellent way of communication. This percentage is less than for WhatsApp. When investigating the reasons for that, students reported that this is the first time of using slack, there fore they are not familiar with it.

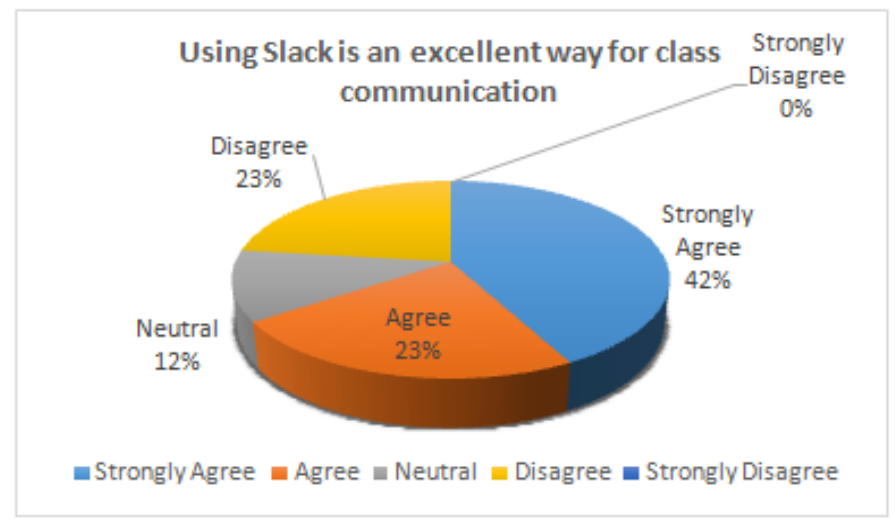

Figure 6. Communication Using Slack

A more detailed survey was conducted in 2018, the results of this survey are shown in Figure 7 to Figure 11. Students are positive in general in using Slack. 79\% of the students agree or strongly agree that it was an excellent way of communication.

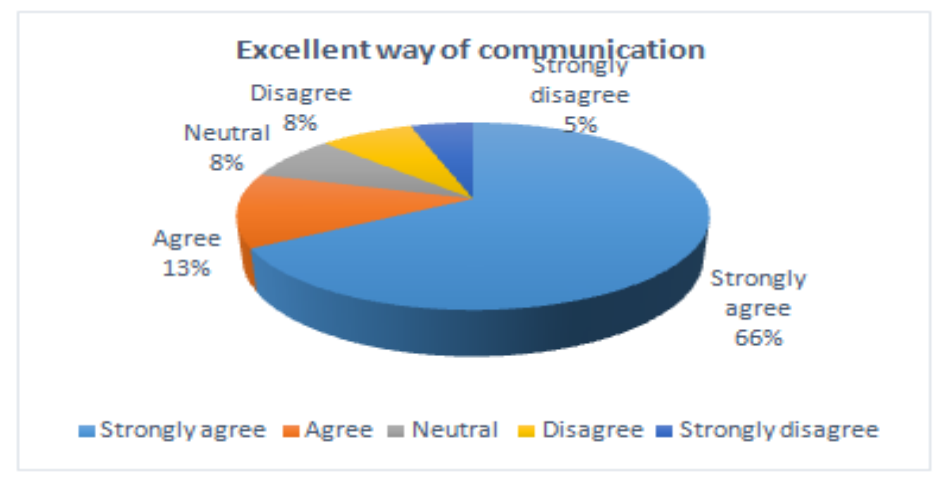

Figure 7. Excellent way of communication 
International Journal on Integrating Technology in Education (IJITE) Vol.7, No.2, June 2018

With respect to the discussion questions, as can be seen from Figure $8,79 \%$ of the students either agree or strongly agree that the discussion questions posted on Slack were useful.

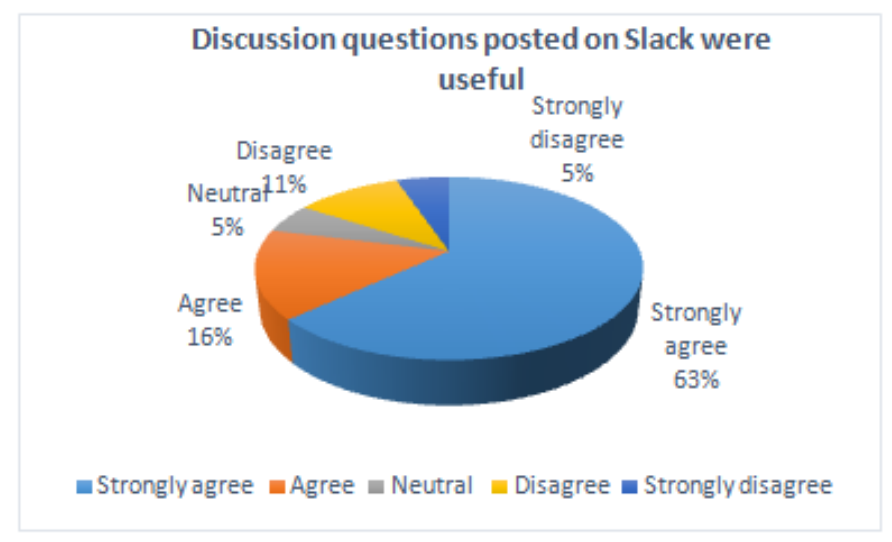

Figure8. Discussion questions on Slack

As can be seen from Figure $9,69 \%$ of the students feel that using Slack made them more engaged with the course.

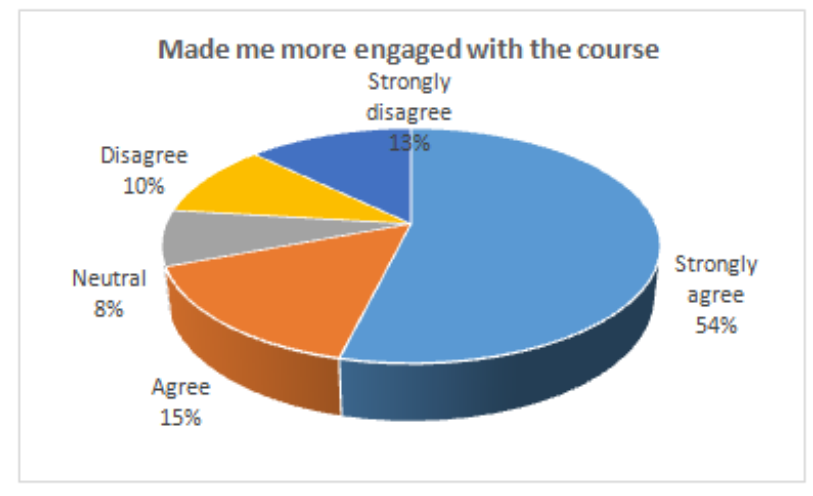

Figure 9. Engagement with the course

$86 \%$ of the students confirm that using Slack enabled them to have better communication with the instructor.

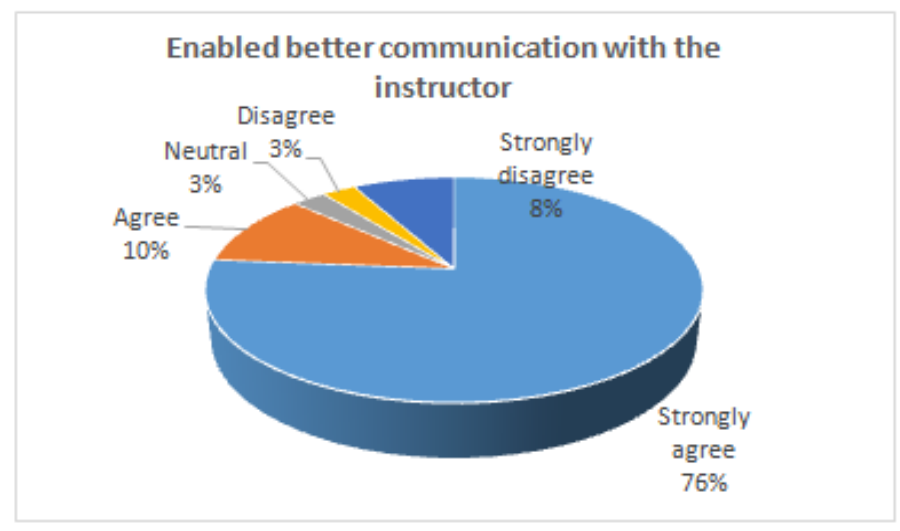

Figure 10. Communication with the instructor 
Finally, $79 \%$ of the students recommend using Slack in the future offering of the course.

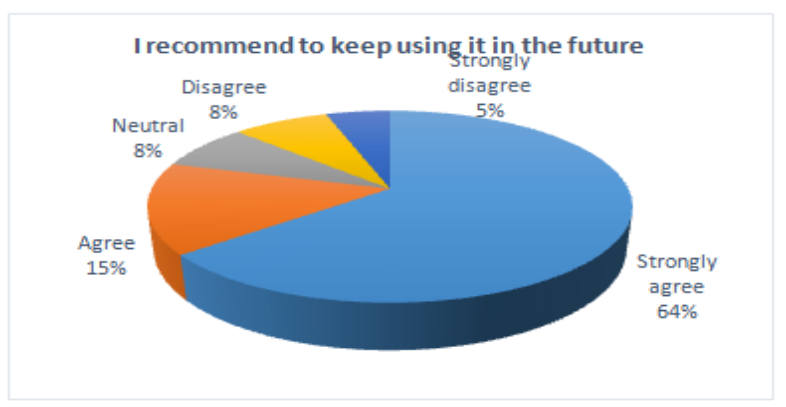

\subsection{TEChNOLOGY USE}

Figure 11. Recommendation to use it in the future

In addition to the surveys for the social media technologies, questions on using technology in the class. In 2011 survey, as shown in Figure 12, in response to the question "Using technology in teaching this course enhanced my learning experience", $100 \%$ of the students either strongly agree or agree that using technology in teaching this course enhanced their learning experience.

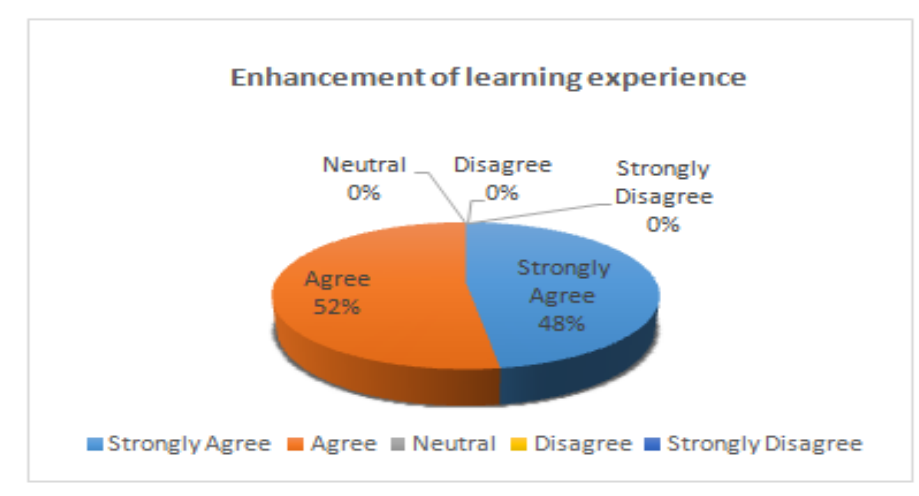

Figure 12: Using technology in enhancing the learning experience

More questions were added to the survey that was done in 2015. It included questions to evaluate students' engagement and satisfaction. In response to the question: "The use of technology made the course more interesting", $100 \%$ of the students either strongly agree or agree that using technology in the course made the course more interesting as shown in Figure 13.

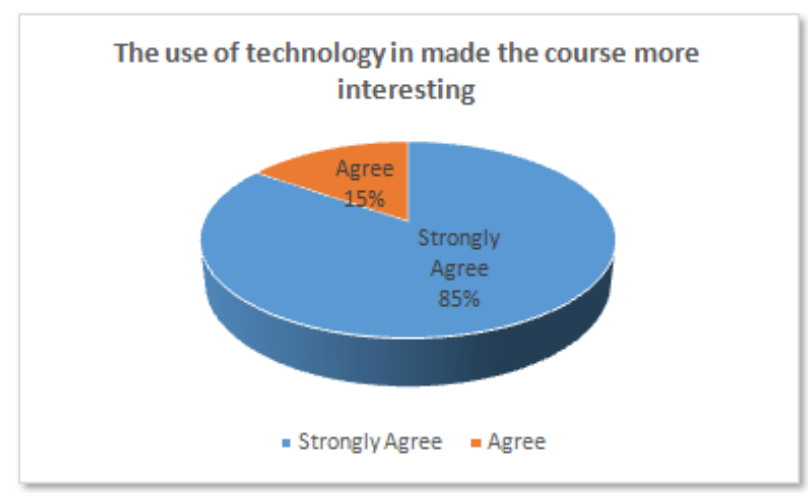

Figure 13: The Use Of Technology In Made The Course More Interesting 
International Journal on Integrating Technology in Education (IJITE) Vol.7, No.2, June 2018

In response to the question: "The use of technology made me more interested in the course", $100 \%$ of the students either strongly agree or agree that using technology in the course made them more interested in the course as shown in Figure 14

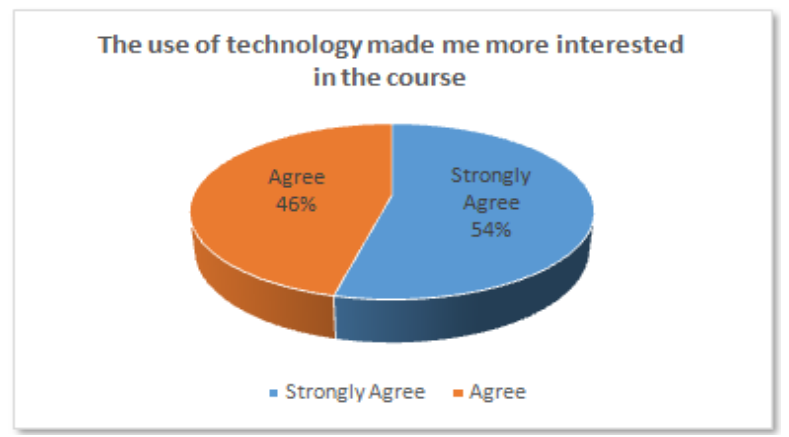

Figure 14: The use of technology and interest in the course

$92 \%$ of the students either strongly agree or agree (while the others are neutral) that that using technology in the course enabled effective communications among students as shown in Figure 15.

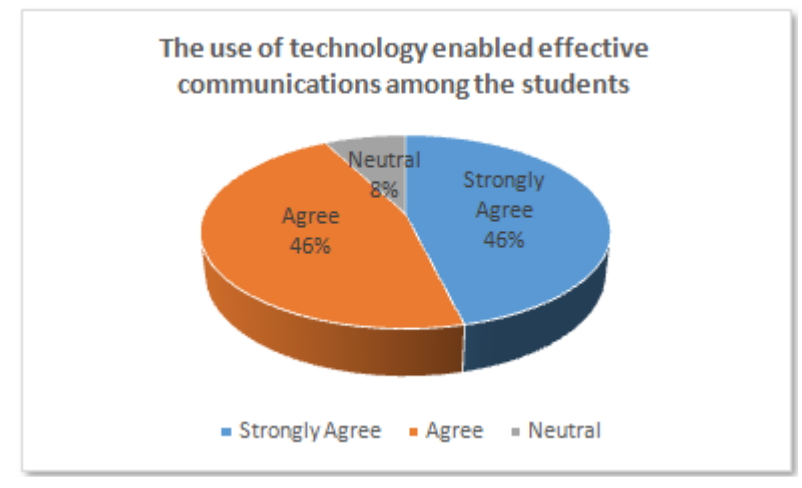

Figure 15: The use of technology and effective communications among students

All students (100\%) either strongly agree or agree that using technology in the course enabled effective communication between the students and the instructor as shown in Figure 16.

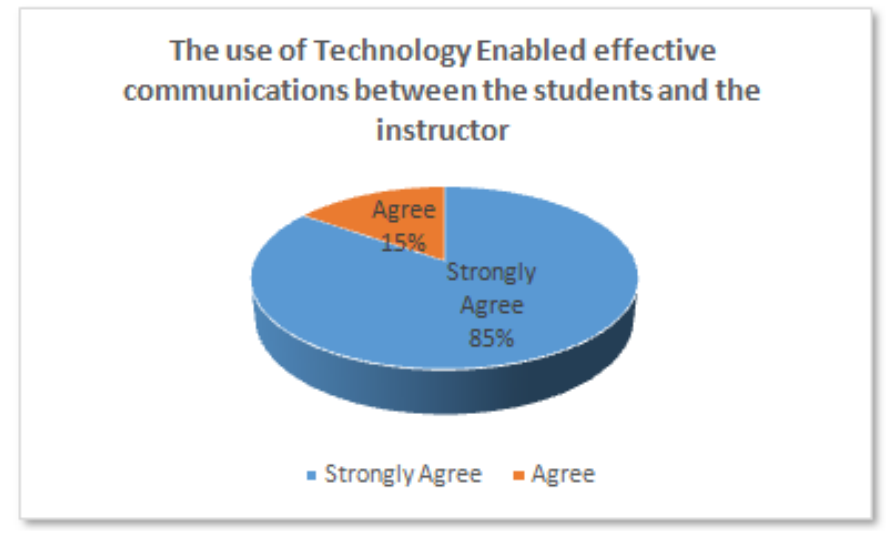

Figure 16: The use of technology enabled effective communications between the students and the instructor 
International Journal on Integrating Technology in Education (IJITE) Vol.7, No.2, June 2018

Finally, $100 \%$ of the students strongly agree recommend using different technologies in the future offering of the course as shown in Figure 17

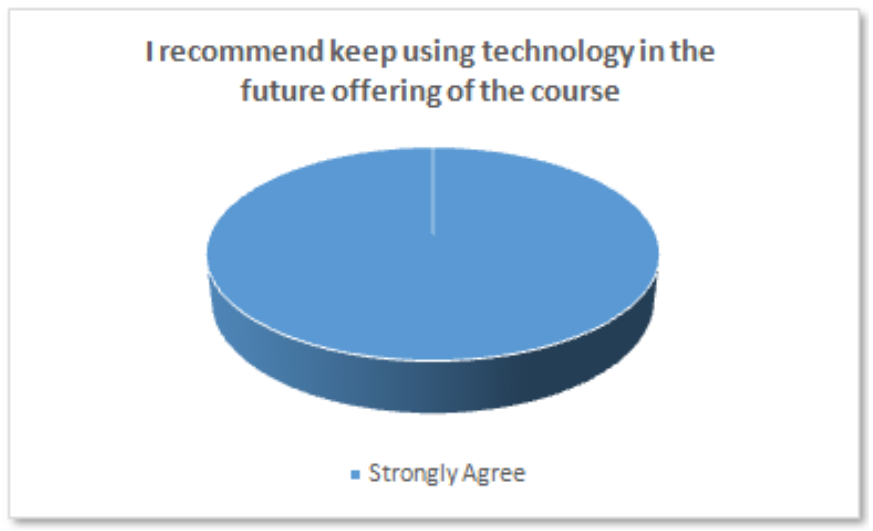

Figure 17: Recommendation of using technology in the future

\subsection{Benefits Of USing Social Media Technologies}

Social media can have different benefits to the students, some of the observed benefits are:

1. Increased the students' engagement with the course which usually has an impact on class performance.

2. Enhanced the communication between the instructor and the students

3. Enhanced the communication between the students themselves.

4. Extended the communication for more than the lecture time including the online office hours

5. Provided the students with a convenient way to ask and answer discussion questions,

6. Created a referable record of course discussions.

7. Helped the instructor to identify concepts that need further discussion

8. Helped in enhancing critical thinking by students.

\section{CONCLUSION}

Social media tools provide interactive environment for communication. This paper presents our experience in using three different social media technologies to enhance students' engagement. We presented our experience with using Facebook for four yearsthen moved to use WhatsApp based on students' request and the instructor's evaluation. Finally, Slack tool was used as a new method for communication.

Our results show that the three methods were found to be effective in promoting students' engagement. However, students seem to be less satisfied when using Slack. This is attributed to the fact that most students never used it before and hence they were not familiar with it, yet, majority were satisfied.

In our future studies, we plan to evaluate the impact of students' performance in using social media tools and technologies, in addition, we plan to evaluate the impact of using gamification technologies in students' engagement and performance.

\section{ACKNOWLEDGEMENT}

The authors acknowledge the support of King Fahd University of Petroleum and Minerals. 
International Journal on Integrating Technology in Education (IJITE) Vol.7, No.2, June 2018

\section{REFERENCES}

[1] A. K. Aggarwal and R. Bent, "Web based education, In learning and teaching Technologies," WebBased Opportunities and Challenges, pp. 2-16, 2000.

[2] A. F. Grasha and H. N. Yangarber, "Integrating teaching styles and learning styles with instructional technology," College Teaching, vol. 48, no. 1, pp. 2-9, 2009.

[3] E.-S. Aziz, "Teaching and Learning Enhancement in Undergraduate Machine Dynamics," Computer Applications in Engineering Education, vol. 19, no. 2, pp. 244-255, 2011.

[4] M. Alshayeb, "Using Software Technologies to Enhance Students Learning: An Experience in Software Project Management Course," International Journal of Technology Diffusion, Vol 6, No. 3, vol. 6, no. 3, 2015.

[5] M. Alavi and R. B. Gallupe, "Using Information Technology in Learning: Case Studies in Business and Management Education Programs," Academy of Management Learning \& Education, vol. 2, no. 2, pp. 139-153, 2003.

[6] A. Bray and B. Tangney, "Enhancing student engagement through the affordances of mobile technology: a 21st century learning perspective on Realistic Mathematics Education," Mathematics Education Research Journal, journal article vol. 28, no. 1, pp. 173-197, March 012016.

[7] L. Proserpio and D. Gioia, "Teaching the virtual generation," Academy of Management Learning and Education, vol. 6, no. 1, pp. 69-80, 2007.

[8] E. Cutrim Schmid, "Potential pedagogical benefits and drawbacks of multimedia use in the English language classroom equipped with interactive whiteboard technology," Computers \& Education, vol. 51, no. 4, pp. 1553-1568, 2008.

[9] J. Farmer, "Communication dynamics: Discussion boards, weblogs and the development of communities of inquiry in online learning environments," in Conference of the Australasian Society for Computers in Learning in Tertiary Education, 2004, pp. 1-10.

[10] D. Fichter, "The many forms of e-collaboration: Blogs, wikis, portals, groupware, discussion boards, and instant messaging," Trade Publication, vol. 29, no. 4, pp. 48-50, 2005.

[11] S. L. Connell, "Comparing blogs, wikis, and discussion boards as collaborative learning tools," in "In Wiki, Hyderabad: India: ICFAI (the Institute of Financial Analysts of India) University Press.," 2006.

[12] S. Gunuc and A. Kuzu, "Confirmation of Campus-Class-Technology Model in student engagement: A path analysis," Computers in Human Behavior, vol. 48, pp. 114-125, 2015/07/01/ 2015.

[13] B. Deliktas, "Computer technology for enhancing teaching and learning modules of engineering mechanics," Computer Applications in Engineering Education, vol. 19, no. 3, pp. 421-432, 2011.

[14] R. Beichner et al., "Case study of the physics components of an integrated curriculum. ," American Journal of Physics, vol. 67, pp. S16-S24, 1999.

[15] C. Romero, S. Ventura, and P. d. Bra, "Using mobile and web-based computerized tests to evaluate university students," Computer Applications in Engineering Education, vol. 17, no. 4, pp. 435-447, 2009.

[16] G. Vavoula and M. Sharples, "Challenges in evaluating mobile learning," in Proceedings of the mLearn 2008 Conference, Shropshire, United Kingdom, 2008.

[17] J. P. López, A. Cerezo, J. M. Menéndez, and J. P. Ballesteros, "Usage of mobile devices as collaborative tools for education and preparation of official exams," in 2015 International Symposium on Consumer Electronics (ISCE), 2015, pp. 1-2.

[18] B. Evrim, "A Review of Research on Mobile Learning in Teacher Education," Journal of Educational Technology \& Society, vol. 17, no. 4, pp. 17-32, 2014.

[19] J. L. V. Barbosa, R. Hahn, D. N. F. Barbosa, and W. Segatto, "Intensive use of mobile technologies in a computer engineering course," Computer Applications in Engineering Education, 2012.

[20] M. Ebner and A. Holzinger, "Successful implementation of user-centered game based learning in higher education: An example from civil engineering," Computers \& Education, vol. 49, no. 3, pp. $873-890,11 / / 2007$. 
International Journal on Integrating Technology in Education (IJITE) Vol.7, No.2, June 2018

[21] W. R. Watson, C. J. Mong, and C. A. Harris, "A case study of the in-class use of a video game for teaching high school history," Computers \& Education, vol. 56, no. 2, pp. 466-474, 2011.

[22] V. K. G. Lim, "The IT way of loafing on the job: Cyberloafing, neutralizing and organizational justice," Journal of Organizational Behavior, vol. 23, no. 5, pp. 675-694, 2002.

[23] D. L. McCabe, K. D. Butterfield, and L. K. Trevio, "Academic dishonesty in graduate business programs: Prevalence, causes, and proposed action," Academy of Management learning and Education, vol. 5, no. 3, pp. 294-305, 2006.

[24] S. C. Rockwell and L. A. Singleton, "The effect of the modality of presentation of streaming multimedia on information acquisition," Media Psychology, vol. 9, no. 1, pp. 179-191, 2007.

[25] C. Chou, "Internet Heavy Use and Addiction among Taiwanese College Students: An Online Interview Study," CyberPsychology \& Behavior, vol. 4, no. 5, pp. 573-585, 2004.

[26] H. L. O'Brien and E. G. Toms, "The development and evaluation of a survey to measure user engagement," Journal of the Association for Information Science and Technology, vol. 61, no. 1, pp. 50-69, 2010.

[27] B. Dyson, K. Vickers, J. Turtle, S. Cowan, and A. Tassone, "Evaluating the use of Facebook to increase student engagement and understanding in lecture-based classes," Higher Education, journal article vol. 69, no. 2, pp. 303-313, February 012015.

[28] T. Rashid and H. M. Asghar, "Technology use, self-directed learning, student engagement and academic performance: Examining the interrelations," Computers in Human Behavior, vol. 63, pp. 604-612, 2016/10/01/ 2016.

[29] J. Imlawi, D. Gregg, and J. Karimi, "Student engagement in course-based social networks: The impact of instructor credibility and use of communication," Computers \& Education, vol. 88, pp. 84-96, 2015/10/01/ 2015.

[30] M. Alshayeb, "Promoting student engagement using social media technologies," in the 6th International Conference on Information Technology in Education (ICITE 2018), Dubai, UAE, 2018, pp. 95-105.

[31] Slack. Available: https://slack.com/

[32] P. M. Institute, 6th, Ed. A Guide to the Project Management Body of Knowledge (PMBOK Guide). 2017.

[33] (2018). Blackboard. Available: http://www.blackboard.com/index.html

\section{AUTHOR}

Dr. Mohammad Alshayeb is an Associate Professor at the Information and Computer Science Department, King Fahd University of Petroleum and Minerals, Saudi Arabia. $\mathrm{He}$ received his $\mathrm{MS}$ and $\mathrm{PhD}$ in Computer Science and certificate of Software Engineering from the University of Alabama in Huntsville in 2000, 2002 and 1999 respectively. He received his B.S. in Computer Science from Mutah University, Jordan in 1995. Dr. Alshayeb worked as a senior researcher and Software Engineer and managed software projects in the United States and the Middle East. Dr. Alshayeb

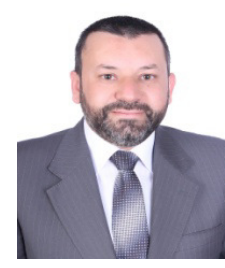
received Khalifa award for education as the distinguished University Professor in the Field of Teaching within Arab World, 2016. Dr. Alshayeb's research interests include software quality and quality improvements, software measurement and metrics, object-oriented design, empirical studies in Software Engineering and engineering education. 